\title{
Implementation of an Exercise Program in Breast Cancer Rehabilitation to Improve Shoulder Outcomes: A Pilot Study
}

\author{
Dragana Ceprnja \\ Westmean Hospital, Dragana.Ceprnja@health.nsw.gov.au \\ Katherine Maka \\ Westmean Hospital
}

Follow this and additional works at: https://nsuworks.nova.edu/ijahsp

Part of the Other Rehabilitation and Therapy Commons, Physical Therapy Commons, and the Physiotherapy Commons

\section{Recommended Citation}

Ceprnja D, Maka K. Implementation of an Exercise Program in Breast Cancer Rehabilitation to Improve Shoulder Outcomes: A Pilot Study. The Internet Journal of Allied Health Sciences and Practice. 2015 Apr 01;13(2), Article 9.

This Manuscript is brought to you for free and open access by the College of Health Care Sciences at NSUWorks. It has been accepted for inclusion in Internet Journal of Allied Health Sciences and Practice by an authorized editor of NSUWorks. For more information, please contact nsuworks@nova.edu. 


\title{
Implementation of an Exercise Program in Breast Cancer Rehabilitation to Improve Shoulder Outcomes: A Pilot Study
}

\begin{abstract}
Purpose: To examine the effects of a group exercise program on shoulder pain, disability, range of motion, and strength. Method: This was an observational study of twenty-six patients who had undergone breast cancer surgery and were receiving physiotherapy intervention. The intervention was a supervised 8-week exercise group program. The primary outcome measure was shoulder pain and disability index (SPADI). Secondary outcome measures were shoulder range of motion of flexion and abduction and strength of shoulder flexion and abduction. Results: The average age of patients referred to the group was 56-years (range of 29 to 71 years). The average time since surgery was 6-9 months (range of 2 to 16 months). The exercise group intervention resulted in small reductions in SPADI scores (pConclusion: An 8-week group exercise program can be effectively implemented in the clinic without any seen side effects. There were improvements in shoulder range of motion and strength, and a reduction in pain and disability although not clinically significant. This pilot study assists clinicians with incorporating an exercise program for patients in breast cancer rehabilitation.
\end{abstract}




\title{
IIAHSP
}

\section{The Internet Joưnal of Allied Health Sciences and Practice}

Dedicated to allied health professional practice and education

Vol. 13 No. 2 ISSN 1540-580X

\section{Implementation of an Exercise Program in Breast Cancer Rehabilitation to Improve Shoulder Outcomes: A Pilot Study}

\author{
Dragana Ceprnja B.Phty (HONS) ${ }^{1}$ \\ Katherine Maka B.AppSci (Phty) ${ }^{2}$
}

1. Health Professional Educator, Physiotherapy Department, Westmead Hospital, Sydney, New South Wales

2. Senior Physiotherapist in Musculoskeletal, Physiotherapy Department, Westmead Hospital, Sydney, New South Wales

Australia

\begin{abstract}
Purpose: To examine the effects of a group exercise program on shoulder pain, disability, range of motion, and strength. Method: This was an observational study of twenty-six patients who had undergone breast cancer surgery and were receiving physiotherapy intervention. The intervention was a supervised 8-week exercise group program. The primary outcome measure was shoulder pain and disability index (SPADI). Secondary outcome measures were shoulder range of motion of flexion and abduction and strength of shoulder flexion and abduction. Results: The average age of patients referred to the group was 56years (range of 29 to 71 years). The average time since surgery was 6-9 months (range of 2 to 16 months). The exercise group intervention resulted in small reductions in SPADI scores $(p<0.001)$, small improvements in shoulder flexion ROM $\left(3.3^{\circ}\right.$ degrees) $(p=0.001)$ and shoulder abduction ROM $\left(3.2^{\circ}\right)(p=0.003)$, and small increases in shoulder flexion strength $(0.37 \mathrm{lbs})(p<0.001)$ and shoulder abduction strength $(0.69 \mathrm{lbs})(\mathrm{p}=0.001)$. No adverse effects were reported during this study. Conclusion: An 8week group exercise program can be effectively implemented in the clinic without any seen side effects. There were improvements in shoulder range of motion and strength, and a reduction in pain and disability although not clinically significant. This pilot study assists clinicians with incorporating an exercise program for patients in breast cancer rehabilitation.
\end{abstract}

\section{INTRODUCTION}

Upper limb impairments in range of motion and strength, and reduced physical fitness are common long term problems experienced after surgery and treatment for breast cancer. ${ }^{1-5}$ These impairments can reduce the ability to perform daily functional activities and return to work and impact one's health-related quality of life. ${ }^{5-8}$ Exercise has been shown to be effective in diminishing many of the side effects from breast cancer and its treatments. $5,9-16$

Exercise has been shown to improve the physical function of breast cancer survivors and quality of life in several high quality studies. ${ }^{6,8,9,12,15,17-21}$ Exercise has been shown to be beneficial in symptom management for patients receiving adjuvant therapy such as chemotherapy and/or radiotherapy. ${ }^{22-26}$ Furthermore, upper body exercise, including resistance exercise, is safe for women at risk for or with lymphedema following breast cancer.1,12,27-30

Based on the evidence, an exercise program for patients with breast cancer has clear health benefits and should be an integral component of rehabilitation. Therefore, we implemented an exercise program in our clinic and examined the effects on pain and disability, shoulder range of motion, and strength. It was hypothesized that there would be a decrease in pain and disability scores, an improvement in shoulder range of motion, and an increase in strength.

\section{METHOD}

\section{Design}

An observational single-centre pilot study was performed. The study was approved by the hospital Human Ethics Committee. All participants provided written informed consent. 


\section{Setting}

The trial was conducted in the Physiotherapy Department of Westmead Hospital, Sydney, NSW Australia.

\section{Participants}

Participants were recruited from a sample of convenience for the study from their physiotherapist or breast care nurse. Women were eligible for the study if they had undergone surgery for diagnosed breast cancer, could attend exercise group sessions, and were able to provide consent. Women who had completed or were undergoing adjunct treatments such as chemotherapy and/or radiotherapy were included. Women were excluded if they were unable to engage in a regular exercise program due to cardiac disease, acute or chronic respiratory disease, or any other uncontrolled medical condition. Participants could withdraw from the trial at any time without prejudice, as set out in the patient information and consent form. Information on participant age, type of surgery, time since surgery, and if they were undergoing adjuvant treatment during intervention were taken.

\section{Intervention}

Participants attended a weekly supervised exercise session for 8 weeks. The group size varied between 5 and 8 participants per session. All participants exercised within this group once per week for 8 weeks. The group was conducted between July 2012 and October 2013. The session was 60 minutes in duration and consisted of a warm up of 10-minutes with light aerobic activity, which may have included outdoor walking, treadmill, stationary bike, or stepper as selected by the supervising physiotherapist according to participant ability or need. Stretches involving large muscle groups such as triceps, quadriceps, hamstrings, calf, were performed actively. The exercise component consisted of 30 minutes of strengthening exercises for the major muscle groups. The supervising physiotherapist tailored the exercise program to meet the individual needs of each participant based on their physical assessment and consideration of adjuvant treatment. The exercises performed were biceps curls, triceps curls, upper limb rowing, squats, step ups, modified abdominal curl ups, bridging, and core stability on an exercise ball. The exercises enabled progression to accommodate increases in strength gained over the course of the program. Free weights were used with 0.5 increments in weight. Participants were instructed to perform 2 sets of 8 to 12 repetitions of each exercise. Resistance was increased by $0.5 \mathrm{~kg}$ when they could complete 3 sets of 15 repetitions. Participants were instructed to exercise at a moderate intensity, which is the equivalent to a rate of perceived exertion on the Borg Scale of no more than 13 out of a possible 20, described as "somewhat hard." 31 Cool down was 10 minutes comprised of light aerobic activity, stretches, and breathing exercises. All patients who had a compression garment were encouraged to wear it during exercise in line with other exercise trials. ${ }^{32}$ Adverse effects were monitored. At the conclusion of the trial, women were encouraged to continue with the program.

\section{Outcome Measures}

Measures were taken at baseline and after intervention at 8 weeks by the same physiotherapist. The shoulder pain and disability index (SPADI) was utilized; a higher score indicates more pain and disability. ${ }^{33}$ Shoulder range of motion (ROM) of the affected arm for flexion and abduction was measured in sitting with the same two arm goniometer. The final result was recorded in degrees as the best of three attempts where a higher score indicates increased range of motion. Maximal isometric shoulder strength measures were taken with a hand-held dynamometer. Shoulder flexion and abduction were measured in sitting with the arm by side with elbow flexed at 90 degrees. The dynamometer was positioned two $\mathrm{cm}$ proximal to the elbow crease for measures. The final result was recorded in pounds (lbs) as the best of three attempts where a higher score indicates more strength.

\section{Statistical Analyses}

Descriptive statistics for age, type of surgery, and time since surgery were made. Data was examined and parametric analyses conducted. The mean within patient change was determined for outcome measures using paired samples t-tests. Mean and standard deviation are reported. Analyses were conducted with SPSS (version 19, IBM, USA 2010).

\section{RESULTS}

The study recruited 32 participants. Twenty-six participants completed the 8 week group program. The demographics of the participants are described in Table 1. The six participants that dropped out of the study were unable to attend for the following reasons: return to work (3), unable to organize childcare (1), further surgery (1) and moved away (1). The average number of sessions attended for drop outs was 4 . The average age of patients referred to the group was 55 -years (range of 24 to 71 years). The average time since surgery was 8.2 months (range of 2 to 16 months). All participants attended 8 sessions of the exercise program over an average of 8.3 weeks (range 8 to 12 weeks). 
Table 1. Demographics

\begin{tabular}{|l|l|l|l|l|}
\hline \multicolumn{1}{|c|}{ Participant } & \multicolumn{1}{|c|}{ Surgery } & $\begin{array}{l}\text { Time Since Surgery } \\
\text { (Months) }\end{array}$ & $\begin{array}{l}\text { Adjunct Treatment } \\
\text { During Intervention }\end{array}$ \\
\hline 1 & 54 & Mx & 6 & Chemotherapy \\
\hline 2 & 61 & Mx \& ALND & 8 & Chemotherapy \\
\hline 3 & 65 & WLE & 6 & - \\
\hline 4 & 68 & WLE & 4 & - \\
\hline 5 & 44 & WLE \& ALND & 13 & - \\
\hline 6 & 55 & Mx & 7 & Radiotherapy \\
\hline 7 & 56 & Mx \& ALND & 8 & - \\
\hline 8 & 24 & Mx \& ALND & 6 & Chemotherapy \\
\hline 9 & 31 & WLE & 12 & - \\
\hline 10 & 66 & WLE \& ALND & 5 & - \\
\hline 11 & 43 & Mx & 6 & - \\
\hline 12 & 55 & Mx & 7 & - \\
\hline 13 & 48 & Mx \& ALND & 5 & Radiotherapy \\
\hline 14 & 59 & WLE & 3 & - \\
\hline 15 & 66 & Mx & 8 & - \\
\hline 16 & 51 & Mx \& ALND & 11 & - \\
\hline 17 & 59 & Mx & 4 & - \\
\hline 18 & 71 & WLE & 2 & - \\
\hline 19 & 70 & Mx \& ALND & 16 & - \\
\hline 20 & 68 & WLE & 14 & - \\
\hline 21 & 62 & WLE & 12 & - \\
\hline 22 & 56 & Mx \& ALND & 12 & - \\
\hline 23 & 32 & Mx & 6 & - \\
\hline 24 & 39 & Mx & 11 & - \\
\hline 25 & 69 & WLE \& ALND & 6 & - \\
\hline 26 & 60 & WLE & 16 & - \\
\hline $4 x=m a t o m y$ & & & & \\
\hline
\end{tabular}

\section{$M x=$ mastectomy}

$A L N D=$ axillary lymph node dissections

$W L E=$ wide local excision

Table 2 displays the mean SPADI, shoulder ROM, and shoulder strength scores before and after intervention for the 26 participants who completed the 8 week intervention. The mean within patient change for the SPADI was $-8.1(95 \% \mathrm{Cl}-4.8$ to $11.5, p<0.001)$. Analysis to compare the pain and disability subsections of the SPADI revealed the change was relatively equal across both sections. The mean within patient change for flexion range was $3.3^{\circ}(95 \% \mathrm{Cl} 1.5$ to $5.1, p=0.001)$. The mean within patient change for abduction range was $3.2^{\circ}(95 \% \mathrm{Cl} 1.2$ to $5.2, \mathrm{p}=0.003)$. The mean within patient change for shoulder flexion strength was $0.37 \mathrm{lbs}(95 \% \mathrm{Cl} 0.18$ to $0.55, p<0.001)$. The mean within patient change for shoulder abduction strength was 0.69 Ibs $(95 \% \mathrm{Cl} 0.31$ to $1.08, p=0.001)$.

\begin{tabular}{|l|l|l|l|}
\hline & Mean Before Intervention & \multicolumn{1}{|c|}{$\begin{array}{c}\text { Mean After } \\
\text { Intervention }\end{array}$} & \multicolumn{1}{|c|}{$\begin{array}{c}\text { Mean Within Patient } \\
\text { Change }\end{array}$} \\
\hline SPADI & 31.8 & 23.7 & $8.1(p<0.001)$ \\
\hline Shoulder ROM & & & $3.3(p<0.001)$ \\
\hline Flexion & $138.4^{\circ}$ & $141.7^{\circ}$ & $3.2(p<0.003)$ \\
\hline Abduction & $135.6^{\circ}$ & $138.8^{\circ}$ & \\
\hline Shoulder strength & & & $0.37(\mathrm{lbs})(\mathrm{p}<0.001)$ \\
\hline Flexion & $11.4(\mathrm{lbs})$ & $11.8(\mathrm{lbs})$ & $0.69(\mathrm{lbs})(\mathrm{p}<0.001)$ \\
\hline Abduction & $11.1(\mathrm{lbs})$ & $11.8(\mathrm{lbs})$ & \\
\hline
\end{tabular}

No adverse effects or complications were reported during the intervention or at follow up. 


\section{DISCUSSION}

The results of the present study led us to conclude that an 8-week exercise program has positive effects on pain and disability, shoulder range of motion, and strength in breast cancer patients who completed the intervention. The SPADI has been used previously in breast cancer patients and has shown a significant relationship between reduced shoulder muscle function and increased SPADI scores in post-operative breast cancer patients.4,34 Our results showed significant improvement of scores, but that change was small. It has been reported that minimal detectable change with $90 \%$ confidence is 13 points and change less than this may be attributable to measurement error. ${ }^{33}$ Our sample had low to moderate pain and disability scores to begin with, so a change in the score is not likely to be as high as it may be with a population who had moderate to high scores at the start of the study. Shamley et al found higher pain scores in patients who had undergone mastectomy compared with wide local excision. ${ }^{4}$ Our sample consisted of $58 \%$ of participants having mastectomy versus $42 \%$ having wide local excision, so perhaps that is why the pain and disability score in our study were not as high. Both pain and disability sections of the SPADI showed relatively equal change across time in our study.

Our results add to the body of evidence that exercise programs can be utilized after breast cancer surgery. ${ }^{24,27,35}$ The increases in muscle strength seen in our study are small when compared with the increases reported by other studies and may represent measurement error. ${ }^{24}$ Courneya et al asked participants to exercise three times a week, which was not a feature of our study. ${ }^{24}$ Considering our program included similar upper limb resisted exercises to their study, it seems likely that exercising more during the week may lead to larger increases in strength. Introduction to the exercise program did not cause any reported adverse effects, including no report of lymphedema symptoms or exacerbation in line with previous studies. 12,24,27,36

This present study has some limitations. In the absence of a control group, it is not known whether the small improvements seen may have occurred due to healing over time. As there was no randomization, the effect size may be overestimated. ${ }^{9}$ Bias may have occurred as the physiotherapist performing the outcome measures was the same physiotherapist who supervised the intervention. However, the primary outcome was a self-administered questionnaire reducing assessor bias. The sample was one of convenience; hence, the generalizability of findings to other breast cancer populations is limited. Furthermore the setting was a single site physiotherapy outpatient department of a large tertiary public hospital, so the applicability of these findings to other settings is unknown. Participant expectancy may also have increased effects; however, participants were blinded to the experimental hypotheses. The constraints of the present pilot study, performed without additional funding or staffing in a busy clinical hospital setting, precluded us from exploring the effects of an exercise group intervention on other health domains, such as quality of life and physical fitness measures.

\section{CONCLUSION}

This study provides some empirical evidence that a group exercise program for breast cancer patients can be effectively implemented in the clinic with small improvements in reported pain and disability without any side effects. Future studies may provide more information to support the role and effectiveness of group exercise programs in the clinical setting in the management and rehabilitation of breast cancer patients.

\section{REFERENCES}

1. Hayes SC, Johansson K, Stout NL, Prosnitz R, Armer JM, Gabram S, Schmitz KH. Upper-body morbidity after breast cancer: incidence and evidence for evaluation, prevention, and management within a prospective surveillance model of care. Cancer. 2012;118:2237-49. [PMID 22488698]

2. Crosbie J, Kilbreath SL, Dylke E, Refshauge KM, Nicholson LL, Beith JM, Spillane AJ, White K. Effects of mastectomy on shoulder and spinal kinematics during bilateral upper-limb movement. Phys Ther. 2010;90:679-92. [PMID 20223945]

3. Ebaugh D, Spinalli B, Schmitz KH. Shoulder impairments and their association with symptomatic rotator cuff disease in breast cancer survivor. Med Hypotheses. 2011;77:481-7. [PMID 21764521]

4. Shamley D, Lascurain-Aguirrebena I, Oskrochi R, Srimaganathan R. Shoulder morbidity after treatment for breast cancer is bilateral and greater after mastectomy. Acta Oncol. 2012;51:1045-53. [PMID 22731831]

5. Penttinen HM, Saarto T, Kellokumpa-Lehtinen P, Blomqvist C, Huovinen R, Kautiainen H, Jarvenpaa S, Nikander R, Idman I, Luoto R, Sievanen H, Utriainen M, Vehmanen L, Jasskelainen AS, Elme A, Ruohola J, Luoma M, Hakamies-Blomqvist L. Quality of life and physical performance and activity of breast cancer patients after adjuvant treatments. Psychooncology. 2011;20:1211-20. [PMID 20878646]

6. Daley AJ, Crank H, Saxton JM, Mutrie N, Coleman R, Roalfe A. Randomized trial of exercise therapy in women treated for breast cancer. J Clin Oncol. 2007;25:1713-21. [PMID 17470863]

(c) The Internet Journal of Allied Health Sciences and Practice, 2015 
7. Campbell KL, Pusic AL, Zucker DS, McNeely ML, Binkley JM, Cheville AL, Harwood KJ. A prospective model of care for breast cancer rehabilitation: function. Cancer. 2012;118:2300-11. [PMID 22488704]

8. Mishra SI, Scherer RW, Synder C, Geigle PM, Berlanstein DR, Topaglu O. Exercise interventions on health-related quality of life for people with cancer during active treatment. Cochrane Database Syst Rev. 2012 CD008465. [PMID 22895974]

9. Fong DYT, Ho JWC, Hui BPH, Lee AM, Macfarlane DJ, Leung SSK, Cerin E, Chan WYY, Leung IPF, Lam SHS, Taylor AJ, Cheng K. Physical activity for cancer survivors: meta-analysis of randomized controlled trials. BMJ.2012;344:(e70)doi:10.1136. [PMID 22294757]

10. McNeely ML, Campbell KL, Rowe BH, Klassen TP, Mackey JR, Courneya KS. Effects of exercise on breast cancer patients and survivors: a systematic review and meta-analysis. CMAJ. 2006;175:34-41. [PMID 16818906]

11. Milne HM, Wallman KE, Gordon S, Courneya KS. Effects of a combined aerobic and resistance exercise program in breast cancer survivors: a randomized controlled trial. Breast Cancer Res Treat. 2008;108:279-88. [PMID 17530428]

12. Comrie P, Pumpa K, Galvao DA, Turner E, Spry N, Saunders C, Zissiadis Y, Newton RU. Is it safe and efficacious for women with lymphedema secondary to breast cancer to lift heavy weights during exercise: a randomized controlled trial. $J$ Cancer Surviv. 2013;7:413-24. [PMID 23604998]

13. Hsieh CC, Sprod LK, Hydock DS, Carter SD, Hayward R, Schneider CM. Effects of supervised exercise intervention on recovery from treatment regimens in breast cancer survivors. Oncol Nurs Forum. 2008;35:909-15. [PMID 18980921]

14. Volakis KA, Halle M, Tokmakidis SP. Exercise in the prevention and rehabilitation of breast cancer. Wiener Klinische Wochenschrift.2013;125:297-301. [PMID 23653151]

15. Schneider CM, Hsieh CC, Sprod LK, Carter SD, Hayward R. Effects of supervised exercise training on cardiopulmonary function and fatigue in breast cancer survivors during and after treatment. Cancer. 2007;110:918-25. [PMID 17582616]

16. Speck RM, Courneya KS, Masse LC, Duval S, Schmitz KH. An update of controlled physical activity trials in cancer survivors: a systematic review and meta-analysis. J Cancer Surviv. 2010;4:87-100. [PMID 20052559]

17. Anderson RT, Kimmick GG, McCoy TP, Hopkins J, Levine E, Miller G, Ribisi P, Mihalko SL. A randomized trial of exercise on well-being and function following breast cancer surgery: the RESTORE trial. J Cancer Surviv. 2012;6:172-81. [PMID 22160629]

18. Herrero F, San Juan AF, Fleck SJ, Balmer J, Perez M, Canete S, Earnest CP, Foster C, Lucia A. Combined aerobic and resistance training in breast cancer survivors: A randomized, controlled pilot trial. Int J Sports Med. 2006;27:573-80. [PMID 16802254]

19. Naumann F, Munro A, Martin E, Magrani P, Buchan J, Smith C, Piggot B, Philpott M. An individual-based versus groupbased exercise and counseling intervention for improving quality of life in breast cancer survivors. A feasibility and efficacy study. Psycho-Oncology. 2012;21:1136-9. [PMID 21726017]

20. Sanchez MJY, Torres Lacomba M, Sanchez Sanchez B, Gutirrez Ortega C, Cerezo Tellez E, Navarro Brazalez B. Effectiveness of physical therapy together with an educational program in the quality of life of breast cancer survivors. Supportive Care in Cancer, conference abstract 2012;20:S252-S253.

21. Harris SR, Schmitz KR, Campbell KL, McNeely ML. Clinical practice guidelines for breast cancer rehabilitation: syntheses of guideline recommendations and qualitative appraisals. Cancer. 2012;118:2312-24. [PMID 22488705]

22. Courneya KS, McKenzie DC, Mackey JR, Gelmon K, Friedenreich CM, Yasui Y, Reid RD, Cook D, Jespersen D, Proulx C, Dolan LB, Forbes CC, Wooding E, Trinh H, Segal RJ. Effects of exercise dose and type during breast cancer chemotherapy: multicenter randomized trial. J Natl Cancer Inst. 2013;105:1821-32. [PMID 24151326]

23. Carayol M, Bernard P, Boiche J, Riou F, Mercier B, Cousson-Gelie F, Romain AJ, Delpierre C, Ninot G. Psychological effect of exercise in women with breast cancer receiving adjuvant therapy: what is the optimal dose needed? Ann Oncol. 2012;24:291-300. [PMID 23041586]

24. Courneya KS, Segal RJ, Mackey JR, Gelmon K, Reid RD, Friedenreich CM, Ladha AB, Proulx C, Vallance JKH, Lane K, Yasui $Y$, McKenzie DC. Effects of aerobic and resistance exercise in breast cancer patients receiving adjuvant chemotherapy: a multicenter randomized controlled trial. J Clin Onc. 2007;25:4396-4404. [PMID 17785708]

25. Markes M, Brockow T, Resch KL. Exercise for women receiving adjuvant therapy for breast cancer. Cochrane Database Syst Rev. 2006;CD005001. [PMID 17054230]

26. Oliveira MM, Souza GA, Miranda MS, Okubo MA, Amaral MT, Silva MP, Gurgel MS. Upper limbs exercises during radiotherapy for breast cancer and quality of life. Rev Bras Ginecol Obstet. 2012;32:133-8.

27. Kilbreath SL, Refshauge KM, Beith JM, Ward LC, Lee M, Simpson JM, Hansen R. Upper limb progressive resistance training and stretching exercises following surgery for early breast cancer: a randomized controlled trial. Breast Cancer Res Treat. 2012;133:667-76. [PMID 22286332]

28. Hayes SC, Speck RM, Reimet E, Stark A, Schmitz KH. Does the effect of weight lifting on lymphedema following breast cancer differ by diagnostic method: results from a randomized controlled trial. Breast Cancer Res Treat. 2011;130:227-34. [PMID 21562712] 
29. Kim do S, Sim YJ, Jeong HJ, Kim GC. Effect of active resistive exercise on breast cancer-related lymphedema: a randomized controlled trial. Arch Phys Med Rehabil. 2010;91:1844-8. [PMID 21112424]

30. Paramanandam VS, Roberts S. Weight training is not harmful for women with breast cancer-related lymphedema: a systematic review. Journal of Physiotherapy. 2014;60:136-143. [PMID 25086730]

31. Borg GA. Psychophysical bases of perceived exertion. Med Sci Sports Exerc. 1982;14:377-381. [PMID 7154893]

32. Schmitz KH. Balancing lymphedema risk: exercise versus deconditioning for breast cancer survivors. Exerc Sport Sci Rev. 2009;38:17-24.

33. Williams JW Jr, Holleman DR Jr, Simel DL. Measuring shoulder function with the Shoulder Pain and Disability Index. J Rheumatol. 1995;22:727-32. [PMID 7791172]

34. Shamley DR, Srinanaganathan R, Weatherall R, Oskrochi R, Watson M, Ostlere S, Sugden E. Changes in shoulder muscle size and activity following treatment for breast cancer. Breast Cancer Res Treat. 2007;106:19-27. [PMID 17221154]

35. Menzel LM, Ferreira VTK, Carrara HHA, Garavello I, Gozzo TO. Randomized controlled clinical study of exercise program on functional and emotional response in women with surgery breast cancer. Supportive care in Cancer, conference abstract 2013;21:S285-86.

36. Ahmed RL, Thomas W, Yee D, Schmitz K. Weight training does not increase incidence of lymphedema in breast cancer survivors. J Clin Oncol. 2006;24:2765-72. 